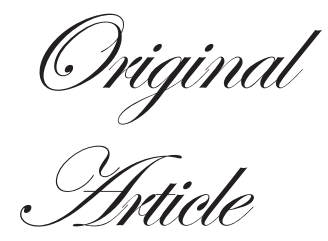

\title{
Role of the lower esophageal sphincter on esophageal acid exposure - a review of over 2000 patients
}

\author{
Kazuto Tsuboi, Masato Hoshino, Abhishek Sundaram, Fumiaki Yano, \\ Sumeet K Mittal
}

\section{ABSTRACT}

Department of Surgery, Creighton University Medical Center, Omaha, Nebraska, 68131, USA

Correspondence:

Dr. Sumeet K Mittal

Email:Skmittal@creighton.edu
Background and aim: Three lower esophageal sphincter (LES) characteristics associated with gastro-esophageal reflux disease (GERD) are, LES pressure $=6 \mathrm{mmHg}$, abdominal length (AL) $<1 \mathrm{~cm}$ and overall length $(\mathrm{OL})<2 \mathrm{~cm}$. The objective of this study was to validate this relationship and evaluate the extent of impact various LES characteristics have on the degree of distal esophageal acid exposure.

Methods: A retrospective review of a prospectively maintained database identified patients who underwent esophageal manometry and $\mathrm{pH}$ studies at Creighton University Medical Center between 1984 and 2008. Patients with esophageal body dysmotility, prior foregut surgery, missing data, no documented symptoms or no $\mathrm{pH}$ study, were excluded. Study subjects were categorized as follows: (1) normal LES (N-LES): patients with LES pressure of 6$26 \mathrm{mmHg}, \mathrm{AL}=1.0 \mathrm{~cm}$ and $\mathrm{OL}=2 \mathrm{~cm}$; (2) incompetent LES (Inc-LES): patients with LES pressure $<6.0 \mathrm{mmHg}$ or $\mathrm{AL}<1 \mathrm{~cm}$ or $\mathrm{OL}<2 \mathrm{~cm}$; and (3) hypertensive LES (HTN-LES): patients with LES pressure $>26.0 \mathrm{mmHg}$ with $\mathrm{AL}=1 \mathrm{~cm}$ and $\mathrm{OL}=2 \mathrm{~cm}$. The DeMeester score was used to compare differences in acid exposure between different groups.

Results: Two thousand and twenty patients satisfied study criteria. Distal esophageal acid exposure as reflected by the DeMeester score in patients with Inc-LES (median=20.05) was significantly higher than in patients with an N-LES (median=9.5), which in turn was significantly higher than in patients with an HTN-LES. Increasing LES pressure and AL provided protection against acid exposure in a graded fashion. Increasing number of inadequate LES characteristics were associated with an increase both in the percentage of patients with abnormal DeMeester score and the degree of acid exposure.

Conclusion: LES pressure $(=6 \mathrm{mmHg})$ and $\mathrm{AL}(<1 \mathrm{~cm})$ are associated with increased lower esophageal acid exposure, and need to be addressed for definitive management of GERD.

KEYWORDS: gastro-esopahgeal reflux disease, lower esophageal sphincter, DeMeester score

\section{Introduction}

Gastro-esophageal reflux disease (GERD) affects between 10 and $20 \%$ of the adult population in the West. ${ }^{1,2}$ While transient lower esophageal sphincter relaxations (TLESR) are probably the most common pathophysiology underlying early GERD, ${ }^{3}$ a structurally defective LES complex (including hiatus hernia) is associated with most severe and medically recalcitrant GERD. ${ }^{4}$ Zaninotto et $\mathrm{al}^{5}$ in a seminal work identified structural LES characteristics associated with increased distal esophageal acid 
exposure. They demonstrated that the abdominal length (AL) and overall length (OL) of the LES are as important as the LES pressure in maintaining the anti-reflux barrier of the LES. ${ }^{5}$ The objective of this study was to revalidate the impact of LES on distal esophageal acid exposure and evaluate the extent of impact the various LES characteristics have on the degree of esophageal acid exposure.

\section{Methods}

Study population

After institutional review board approval, a prospectively maintained database was queried to identify patients who underwent concurrent esophageal manometry and $24 \mathrm{hr} \mathrm{pH}$ studies at the Esophageal center at Creighton University Medical Center (CUMC) between November 1984 and November 2008. All patients completed a standardized symptom questionnaire at the esophageal center, which collects information on the presence/absence, severity (scale: 0-3) and frequency of the following symptoms: heartburn, dysphagia, regurgitation, chest pain, nausea/vomiting and abdominal bloating. Patients with esophageal body dystmotility were excluded to minimize confounding effects on symptoms and acid exposure. Also patients with prior foregut surgery, missing data or no documented symptoms were excluded.

\section{Esophageal manometry}

Manometry was performed using a trans-nasal five-channel catheter with a low-compliance, water infusion system (Medtronic, Minneapolis, MN, USA) using the pull-through method. This has been previously described. ${ }^{5}$ The catheter has 5 circumferential sensors at $5 \mathrm{~cm}$ intervals. A gastric baseline pressure is established. The catheter is then repositioned such that the $5^{\text {th }}$ channel is at the LES (channel at which the pressure rises $>2 \mathrm{mmHg}$ above the gastric baseline). This marks the distal border of the LES. The LES pressure was measured as the difference in $\mathrm{mmHg}$ between the gastric baseline pressure and the pressure at the respiratory inversion point (RIP) during the middle of the respiratory cycle (Figure 1). RIP is where the respiratory variation is opposite to the gastric waveform and this marks the proximal border of the abdominal segment of the LES. Five measurements of sphincter pressure were obtained and averaged in order to obviate the variation of pressures at each orifice due to the radial asymmetry of the sphincter. The proximal border of the LES is the channel at which the pressure

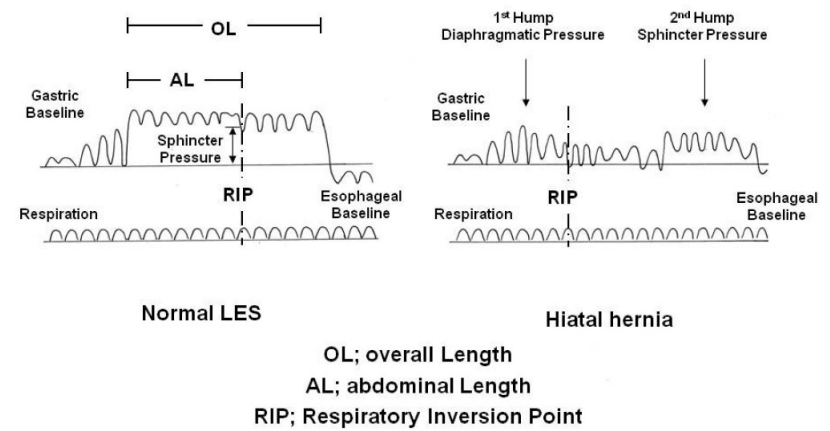

Figure 1: Measurement of lower esophageal sphincter (LES) length

falls below the gastric baseline. AL is the distance between the distal border of the LES and RIP (Figure 1). OL is the distance between the distal and proximal borders of the LES (Figure 1). The distal esophageal amplitude (DEA), AL and OL were reported as the mean of 5 values obtained during the catheter pull through. An $\mathrm{OL}<2 \mathrm{~cm}$ was considered inadequate, while an $\mathrm{AL}<1 \mathrm{~cm}$ was considered inadequate. Esophageal body function was evaluated with ten liquid swallows $(10 \mathrm{cc})$. The DEA was the mean of the pressures at 3 and $8 \mathrm{~cm}$ above the LES.

Patients were considered to have normal esophageal body function if $30 \mathrm{mmHg}<\mathrm{DEA}<180 \mathrm{mmHg}$ with $20 \%$ or less dropped or simultaneous waves in the distal esophagus. Patients were categorized into 3 groups based on LES characteristics which have been previously identified as associated with gastro-esophageal reflux disease: ${ }^{5}(1)$ normal LES (N-LES): patients with as a LES pressure of 6-26 $\mathrm{mmHg}$, $\mathrm{AL} \geq 1.0 \mathrm{~cm}$ and $\mathrm{OL} \geq 2 \mathrm{~cm}$; (2) incompetent LES (Inc-LES): patients with $\mathrm{LES}<6.0 \mathrm{mmHg}$ or $\mathrm{AL}<1 \mathrm{~cm}$ or $\mathrm{OL}<2 \mathrm{~cm}$; and (3) hypertensive LES (HTN-LES): patients with LES pressure $>26.0$ $\mathrm{mmHg}, \mathrm{AL} \geq 1 \mathrm{~cm}$ and $\mathrm{OL} \geq 2 \mathrm{~cm}$. The DeMeester score was used to compare differences in acid exposure between the groups. To evaluate the extent of impact various LES characteristics have on degree of esophageal acid exposure, they were subdivided as follows: (1) LES pressure: $<6 \mathrm{mmHg}, 6-12 \mathrm{mmHg}$, 12-18 mmHg, 18-24 mmHg and > $24 \mathrm{mmHg}$; (2) AL: $<1 \mathrm{~cm}, 1-1.5$ $\mathrm{cm}, 1.5-2 \mathrm{~cm}, 2-2.5 \mathrm{~cm}, 2.5-3 \mathrm{~cm}$ and $>3 \mathrm{~cm}$; (3) O: $0-2 \mathrm{~cm}, 2-3 \mathrm{~cm}$, $3-4 \mathrm{~cm}, 4-5 \mathrm{~cm}, 5-6 \mathrm{~cm}$, and $>6 \mathrm{~cm}$.

\section{4 hour pH study}

Twenty four hour $\mathrm{pH}$ monitoring was performed with either a catheter-based system (Digitrapper 400pH ${ }^{\circledR}$; Medtronic, Minneapolis, MN, USA) or a capsule-based system (Bravo ${ }^{\circledR}$; Medtronic, Minneapolis, MN, USA). The catheter based $\mathrm{pH}$ 
probe was passed trans-nasally and positioned $5 \mathrm{~cm}$ above the upper border of the manometrically defined LES while the capsule was passed trans-orally and positioned $6 \mathrm{~cm}$ above the endoscopic gastro-esophageal junction. For the capsule based system, the DeMeester score was the mean of the scores recorded over 2 days. All studies were conducted while the patient was off anti-reflux medications (proton pump inhibitor $\geq 7$ days, $\mathrm{H}_{2}$ blocker $\geq 3$ days).

\section{Statistical analysis}

Statistical analyses were performed using SPSS version 16.0 (SPSS Inc, Chicago, IL, USA). Continuous variables were analyzed using ANOVA or the Kruskal Wallis test. If there were significant differences with the Kruskal Wallis test, post-hoc analyses were performed using the Mann-Whitney U test. ANOVA performs post hoc analyses if there are significant differences between the groups. Spearman's correlation coefficient was used to analyze correlation between the following groups: (1) LES pressure and DeMeester score, (2) AL and DeMeester score and (3) OL and DeMeester score. A $p$-value of $<0.05$ was considered significant.

\section{Results}

Four thousand six hundred and nine patients underwent esophageal manometry testing during the study period. Patients with esophageal dysmotility $(n=1310)$, history of previous foregut surgery $(n=443)$, missing data $(n=50)$, no documented symptoms $(\mathrm{n}=52)$ and no $\mathrm{pH}$ study $(\mathrm{n}=814)$, were excluded (Figure 2). Two thousand and twenty patients (males: 922, females: 1098) satisfied the study criteria. Nine hundred and four patients had an Inc-LES, 1049 patients had an N-LES, and 67 patients had an HTN-LES (Table 1).

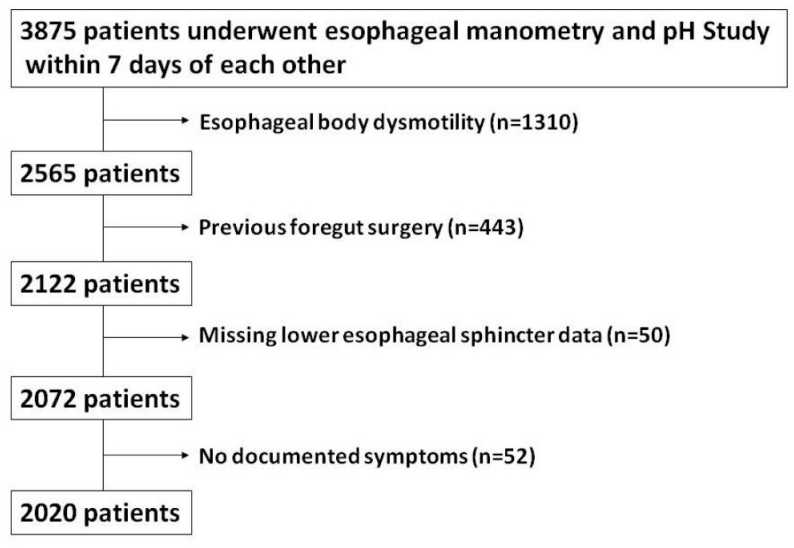

Figure 2: Study population
Impact of LES on acid exposure

Distal esophageal acid exposure as reflected by the DeMeester score in patients with Inc-LES (median=20.05) was significantly higher than in patients with an N-LES (median=9.5), which in turn was significantly higher than in patients with an HTNLES (Table 1).

Table 1: LES and acid exposure

\begin{tabular}{|c|c|c|c|c|}
\hline$\overline{\text { Variable }}$ & $\begin{array}{l}\text { Inc-LES } \dagger \\
(n=904)\end{array}$ & $\begin{array}{l}\text { N-LES } \$ \\
(n=1049)\end{array}$ & $\begin{array}{l}\text { HTN-LES } \\
(n=67)\end{array}$ & p-value \\
\hline Age (median) & $\begin{array}{l}47 \text { yrs } \\
\text { (IQRII: } \\
37-59 \text { yrs) }\end{array}$ & $\begin{array}{l}46 \text { yrs } \\
\text { (IQR I: } \\
36-57 y r s)\end{array}$ & $\begin{array}{l}48 \text { yrs } \\
\text { (IQRII: } \\
\text { 36-63yrs) }\end{array}$ & $0.006 *$ \\
\hline Gender & $\begin{array}{l}\text { Male: } 441 \\
\text { Female: } 463\end{array}$ & $\begin{array}{l}\text { Male: } 456 \\
\text { Female: } 593\end{array}$ & $\begin{array}{l}\text { Male: } 25 \\
\text { Female: } 42\end{array}$ & $\begin{array}{l}0.155 \\
<0.001 *\end{array}$ \\
\hline $\begin{array}{l}\text { DeMeester } \\
\text { score (median) }\end{array}$ & $\begin{array}{l}20.05 \\
\text { (IQRII: } \\
8.025-36.5)\end{array}$ & $\begin{array}{l}9.5 \\
\text { (IQR I: } \\
2.9-22)\end{array}$ & $\begin{array}{l}7.6 \\
\text { (IQR } \llbracket: \\
1.6-16.6)\end{array}$ & $\begin{array}{l}<0.001 * * \\
0.009 * * *\end{array}$ \\
\hline
\end{tabular}

$\dagger-$ Incompetent sphincter

$\$-$ Normal sphincter

$\S$ - Hypertensive sphincter

II - Interquartile range

*= Significant difference between Inc-LES and N-LES

$* *=$ Significant difference between N-LES and HTN-LES

$* * *=$ Significant difference between Inc-LES and HTN-LES

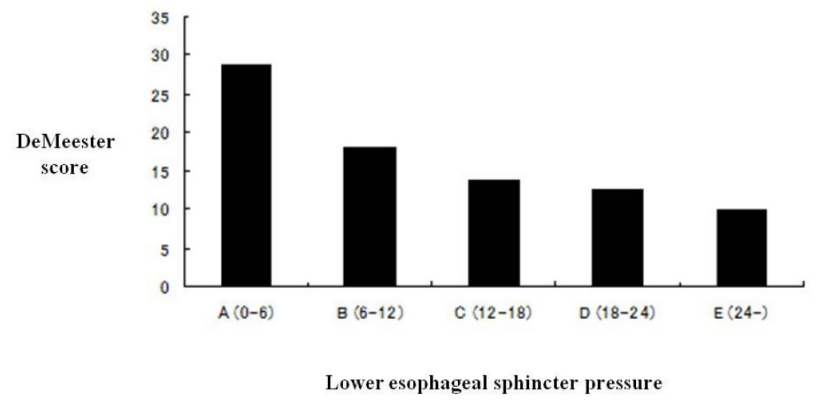

Figure 3a: Impact of lower esophageal sphincter (LES) pressure on DeMeester score

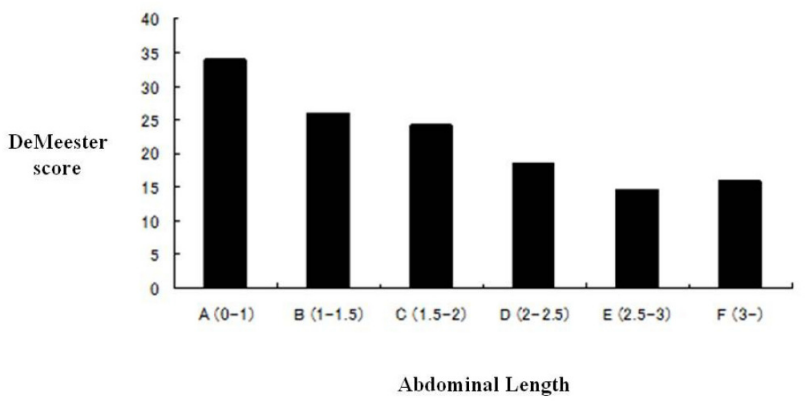

Figure 3b: Impact of abdominal length (AL) on DeMeester score 
As seen in Figures 3 (a) and (b), increasing LES pressure and AL provided protection against esophageal acid exposure in a graded fashion. However, increasing OL was not associated with protection against esophageal acid exposure. Increasing the number of abnormal LES characteristics was associated with an increase in the percentage of patients with abnormal DeMeester score (Figure 4). Also increasing number of incompetent LES characteristics were associated with a significant increase in degree of acid exposure as measured by the DeMeester score (Figure 5).

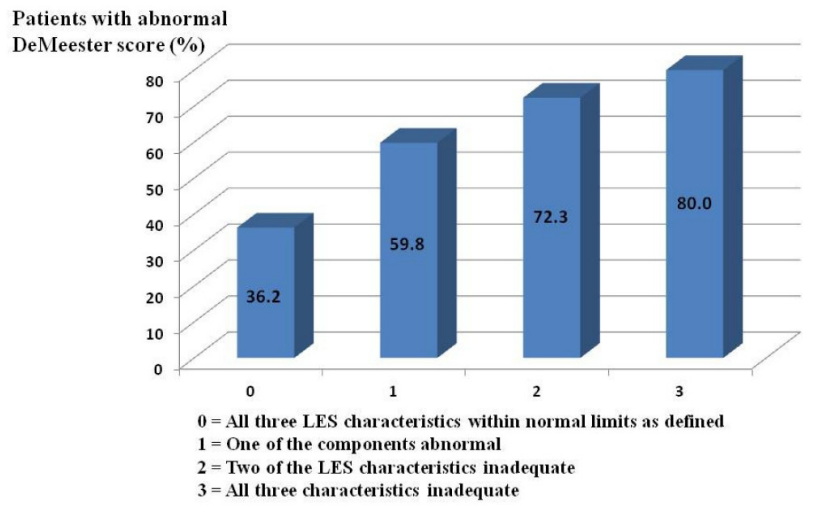

Figure 4: Impact of number of abdominal lower esophageal sphincter (LES) characteristics on abnormal DeMeester score

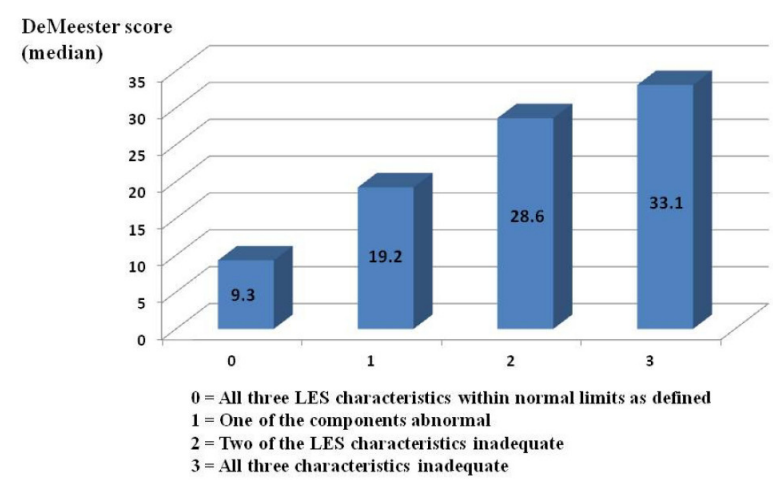

Figure 5: Impact of number of abdominal lower esophageal sphincter (LES) characteristics on DeMeester score

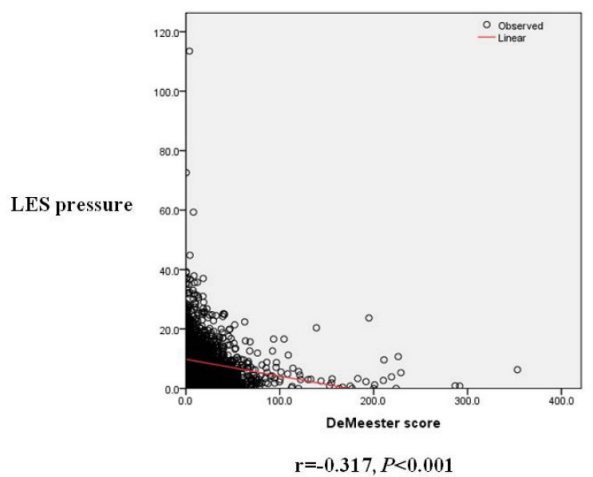

Figure 6: Correlation between lower esophageal sphincter (LES) pressure and DeMeester score

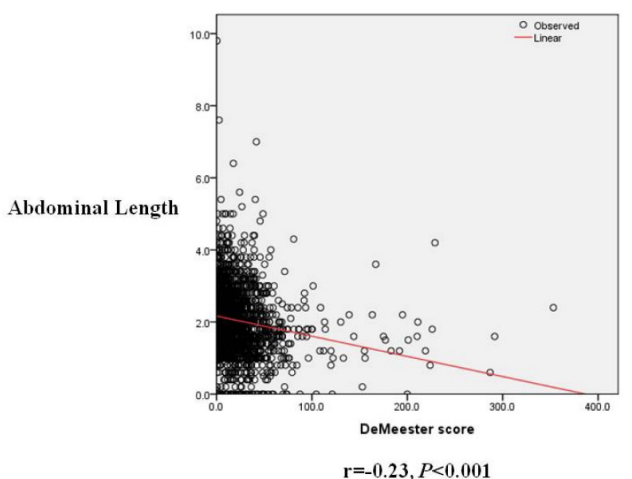

Figure 7: Correlation between abdominal length (AL) and DeMeester score

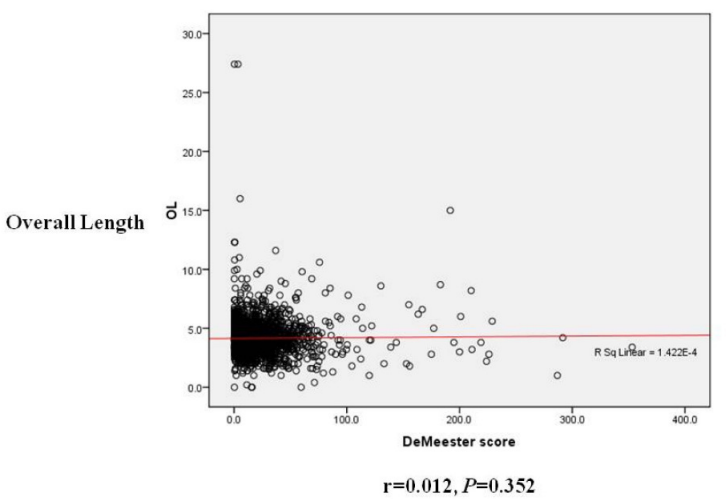

Figure 8: Correlation between overall length (OL) and DeMeester score

Both LES pressure and AL had a significant negative correlation with the DeMeester score (Figures 6 and 7). However, there was no significant correlation between OL and DeMeester score (Figure 8).

\section{Discussion}

In this study, patients with an Inc-LES (LES pressure $\leq 6 \mathrm{mmHg}$ or $\mathrm{AL}<1 \mathrm{~cm}$ or $\mathrm{OL}<2 \mathrm{~cm}$ ) had more severe reflux than the rest of the patients, as reflected by the higher distal esophageal acid exposure. In addition we found that increasing the LES pressure and AL provided a protective barrier against reflux in a graded fashion. Inadequate LES pressure, AL and OL appear to have an additive effect on reflux when present together. As seen in

Figure 4, 60\% of patients with one abnormal component had an abnormal DeMeester score, while $80 \%$ of patients with three abnormal components had an abnormal DeMeester score. Also as the number of inadequate LES characteristics increased so did the degree of reflux as represented by the DeMeester score.

These findings validate those of Zaninotto et al,,$^{5}$ except that we did not find inadequate $\mathrm{OL}(<2 \mathrm{~cm})$ to be associated with increased reflux. The OL is calculated from the first diaphragmatic impression to the top of the LES where the intra- 
luminal esophageal pressure falls below $0 \mathrm{mmHg}$. This creates an inherent problem in our calculations as this overestimates the OL in presence of a hiatus hernia, where a high-pressure deflection of the crus may be marked as the lower border of the LES. The database did not allow for us to review and exclude the tracings of patients with a large hiatus hernia. In these patients the AL would be zero as there is no sphincter pressure below the RIP, but the OL is over estimated (Figure 1).

Resting intra-gastric pressure is higher than the baseline esophageal pressure. In a normal physiological state the highpressure LES complex serves as a mechanical barrier to prevent gastro-esophageal reflux. Permanent or repeated transient incompetence of this barrier results in GERD. ${ }^{3} \mathrm{H}_{2}$ receptor blockers and proton pump inhibitors (PPI) ameliorate symptoms by neutralizing the $\mathrm{pH}$ to varying degrees. However, a change in $\mathrm{pH}$ does not alter the inherent pathophysiological disturbance and hence the reflux continues. Advances in prolonged reflux monitoring using impedance $\mathrm{pH}$ monitoring have clearly documented continued gastro-esophageal reflux (non-acidic or weekly acidic) with acid suppression by PPIs. ${ }^{6}$ It has been demonstrated that definitive surgical management in the form of a fundoplication significantly decreases the frequency of TLESRs and increases LES pressure. ${ }^{7}$ It also allows for repair of a hiatal hernia if present and thus remedies the issue of an inadequate $\mathrm{AL}$.

The limitation of this study is its retrospective nature; however, all data were entered prospectively. Given the long study duration data analyzed were limited to those described in the paper. We were not able to evaluate the impact of TLESRs on reflux as we did not perform $24 \mathrm{hr}$ motility studies. While previous studies have explored the impact of LES on esophageal acid exposure, this study represents the largest systematic evaluation of the impact of LES characteristics on esophageal acid exposure with over 2,000 patients. This study once and for all reconfirms that a competent LES complex is important to prevent gastro-esophageal reflux.

In conclusion, LES characteristics associated with increased distal esophageal acid exposure include LES pressure $\leq 6 \mathrm{mmHg}$ and $\mathrm{AL}<1 \mathrm{~cm}$. Consequently increasing LES pressure and $\mathrm{AL}$ provide protection against reflux in a graded fashion. This should be considered while developing and incorporating endoscopic procedures for treatment of GERD.

\section{References}

1. Dent J, El-Serag HB, Wallander MA, Johansson S. Epidemiology of gastro-oesophageal reflux disease: a systematic review. Gut. 2005;54:710-7.

2. Sandler RS, Everheart JE, Donowitz M, Adams E, Cronin K, Clifford $\mathrm{G}$, et al. The burden of selected digestive diseases in the United States. Gastroenterology. 2002;122:1500-11.

3. Dodds WJ, Dent J, Hogan WJ, Helm JF, Hauser R, Patel GK, et al. Mechanisms of gastroesophageal reflux in patients with reflux esophagitis. N Engl J Med. 1982;307:1547-52.

4. Patti MG, Goldberg HI, Arcerito M, Bortolasi L, Tong J, Way LW. Hiatal hernia size affects lower esophageal sphincter function, esophageal acid exposure, andthe degree of mucosal injury. Am J Surg. 1996;171:182-6.

5. Zaninotto G, DeMeester TR, Schwizer W, Johansson KE, Cheng $\mathrm{SC}$. The lower esophageal sphincter in health and disease. Am J Surg. 1988;155:104-11.

6. Vela MF, Camacho-Lobato L, Srinivasan R, Tutuian R, Katz PO, Castel DO. Simultaneous intraesophageal impedance and $\mathrm{pH}$ measurement of acid and nonacid gastroesophageal reflux: effect of omeprazole. Gastroenterology. 2001;120:1599-606.

7. Lindeboom MY, Vu MK, Ringers J, van Rijn PJ, Neijenhuis P, Masclee AA. Function of the proximal stomach after partial versus complete laparoscopic fundoplication. Am J Gastroenterol. 2003;98:284-90. 